\title{
Outcome of high fetal station in Primi-Gravida at term in labour
}

\author{
Neha Mahajan*, Sheikh Mustafa, Samiya Tabassum, Perveena Fareed
}

Department of Obstetrics \& Gynaecology, LD Hospital, Government Medical College, Srinagar, J\&K, India

Received: 25 January 2016

Accepted: 15 February 2016

*Correspondence:

Dr. Neha Mahajan,

E-mail: doctor3086@gmail.com

Copyright: ( ) the author(s), publisher and licensee Medip Academy. This is an open-access article distributed under the terms of the Creative Commons Attribution Non-Commercial License, which permits unrestricted non-commercial use, distribution, and reproduction in any medium, provided the original work is properly cited.

\begin{abstract}
Background: Labour is an important event with unique experience exclusively in a woman's life, which gives her the greatest satisfaction by delivering her own child, the wonder creation of master craftsman! The objective of the study was to know the effect of station of fetal head in early labour and its significance, to assess the course and duration of labour in relation to station of head at the onset of labour and to study the maternal and neonatal outcome.

Methods: The prospective descriptive study was conducted at the Department of Obstetrics and Gynecology, LD Hospital, Government medical college, Srinagar on 150 primigravida with unengaged head at term and at onset of labour. Detailed history was taken in each case and general, systemic and obstetric examination was done. Pelvic assessment and ultrasonography was performed.

Results: Of the 150 women in the study, 110 (70\%) were aged between 20-30 years. The most common cause of unengaged head was deflexed head in $42(28 \%)$ women, Cephalopelvic disproportion (CPD) in 20 (13.34\%), loop of the cord around the neck in $9(6 \%)$, placenta previa type in $8(5.33 \%)$ whereas no cause could be identified in $60(40 \%)$ Further, Only 67 (44.67\%) women presented with spontaneous labour, and the rest were induced with prostaglandin or with intra-cervical Foleys catheter for varied reasons. Vaginal delivery occurred in $89(59.33 \%)$ cases and caesarean section was performed in $54(36 \%)$. The duration of labour was <12 hours in $32(32 \%)$ cases. Postpartum hemorrhage $(\mathrm{PPH})$ occurred in $16(10.67 \%)$ women, perineal tear in $5(3.33 \%)$, wound infection in $8(5.33 \%)$. Apgar score at 5 minute was 7-10 in 113 (75.33\%), 4-6 in 30 (20\%), 3 and below in 7 (4.67\%) neonates.

Conclusions: The primigravida with unengaged head at term during labour should be regarded with suspicion and the same woman in labour should be regarded with apprehension. Labour appeared to be dysfunction in only small proportion of the patients with unengaged head.
\end{abstract}

Keywords: High head at term, Labour, Non-engaged head, Primigravida

\section{INTRODUCTION}

Labour is an important event with unique experience exclusively in a woman's life, which gives her the greatest satisfaction by delivering her own child, the wonder creation of master craftsman! ${ }^{1}$ Labour is the onset of regular uterine contractions followed by progressive cervical dilatation, effacement and descent of presenting part. $^{2}$ Fetal head is said to be engaged when its widest diameter has fit into the pelvic inlet. ${ }^{3}$ It had been a traditional conception Obstetrics that engagement of fetal head occurs by 38 weeks gestation in primigravida. In majority, engagement occurs between 38 and 42 weeks or even during the first stage of labour. ${ }^{4}$

It is generally accepted that high fetal station in primigravidas in labour near term may indicate a threat to the normal progress of labour because of feto-pelvic disproportion or obstruction of the fetal passage by tumour or the placenta. ${ }^{5}$ Non engagement at the onset of active phase of labour is a predictor of the risk of caesarean section. Surgical interventions are quite high. ${ }^{6}$ Latent phase is prolonged and duration of first stage increased from 12 to 14 hours due to improper adaptation 
of fetal head, high station and misdirection of uterine expulsive forces. 6,7

The problems of prolonged labour are that the woman is exposed to high risk of infection, ketosis and obstructed labour while the fetus faces the danger of asphyxia and infection. $^{6,7}$

In the following study, it has been shown that with careful monitoring of progress of labour and judicial and timely medical intervention it became very much possible to avoid otherwise necessary caesarean sections in most of the primigravidas with high heads. An effort has been made to identify the commonest and significant aetiological factors which lead to non-engagement of the head in such cases.

The objective of the study was to know the effect of station of fetal head in early labour and its significance, to assess the course and duration of labour in relation to station of head at the onset of labour and to study the maternal and neonatal outcome.

\section{METHODS}

The prospective descriptive study was conducted at the Department of Obstetrics and Gynecology, LD Hospital, Government medical college, Srinagar on 150 primigravida with unengaged head at term and at onset of labour during the period between March 2015-June 2015.

\section{Inclusion criteria}

1. Healthy female with no medical disorders like (diabetes mellitus, hyper-tension, cardiac problems, thyroid disorders, renal or hepatic problems).

2. Free floating head or $3 / 5$ th or more of the head was above pelvic prim were included in the study.

3. Full term gestation (between 38 and 42 weeks of gestation).

4. Live singleton fetus.

5. Vertex presentation.

6. No obvious Cephalopelvic disproportion.

7. Intact membrane.

8. Cervix less than $3 \mathrm{~cm}$.

\section{Exclusion criteria}

1. Multigravida.

2. Previous history of abortion.

3. Primi with medical complication like diabetes mellitus and hypertension, etc.

4. Preterm pregnancy or growth restriction as estimated by the date of the last menstrual period and ultrasound scanning.

5. Malpresentation.

All patients signed an informed consent to declare their agreement to be enrolled in the study, as agreed upon by the ethical medical committee.
Full history is taken from each patient including the personal, gynecological and obstetric history. Medical and surgical history is also taken to exclude systemic diseases.

Vital signs were measured for each patient. Abdominal examination for the level of uterine fundus to correlate it with gestational age was done. Investigations in the form of complete blood picture, blood group, coagulation profile were performed.

Ultrasound was done to assess the expected date of delivery, with correlation to gestational age estimated by last menstrual period to exclude any intra-uterine growth restriction (if the patient is sure of her date of last menstrual cycle). The fetal weight, placental site and amniotic fluid index were determined; any fetal anomalies seen were excluded from the recruitment.

Vaginal examination was done and cervical dilatation and effacement were determined on admission. The active labor is determined as cervical dilatation centimeters with regular uterine contractions (3-4 contractions every 10 minutes). The station of the vertex is determined on admission. The Muller Munro Kerr maneuver ${ }^{8}$ was used to assess the adequacy of the pelvis and diagonal conjugate was accurately measured.

Oxytocin was used to augment the patients in need. The Oxytocin infusion rate is adjusted to have 3-4 contractions in 10 minutes. Fetal heart rate is monitored for each primigravida during the labor period.

Artificial rupture of membrane is done, if not spontaneously ruptured before. Amniotic fluid color is inspected whether meconium stained or not after membrane rupture. The labor outcome was assessed. In cases delivered vaginally, the duration of the first and second stage of labor were reported. The indications of Cesarean section were also reported if the patient delivered abdominally. The Apgar score at 1 and 5 minutes were recorded. Fetal weight is measured and recorded. Maternal and fetal morbidity were recorded.

\section{RESULTS}

Of the 150 women, $125(83.33 \%)$ were in the $20-30$ age group. The most common cause of un-engaged head was deflexed head in $42(28 \%)$ women, Cephalopelvic disproportion (CPD) in $20(13.34 \%)$, loop of the cord around the neck in $9(6 \%)$, placenta previa type in 8 $(5.33 \%)$ whereas no cause could be identified in 60 (40\%) (Table 1).

Only $67(44.67 \%)$ women presented with spontaneous labour, and the rest were induced with prostaglandin or with intra-cervical Foleys catheter for varied reasons (Table 2) and most of the women $(90 \%)$ required augmentation with oxytocin (Table 3 ). 
Table 1: Distribution of the cases according to aetiology.

\begin{tabular}{|lll|}
\hline $\begin{array}{l}\text { Apparent } \\
\text { aetiology }\end{array}$ & Number of cases & Percentage \\
\hline $\begin{array}{l}\text { Deflexed head } \\
\begin{array}{l}\text { Cephalopelvic } \\
\text { disproportion }\end{array}\end{array}$ & 42 & 28.00 \\
\hline $\begin{array}{l}\text { Loops of cord } \\
\text { around neck }\end{array}$ & 9 & 13.34 \\
\hline Placenta previa & 8 & 6.00 \\
\hline $\begin{array}{l}\text { Prelabour rupture } \\
\text { of membranes }\end{array}$ & 6 & 5.33 \\
\hline Polyhydramnios & 3 & 4 \\
\hline Hydrocephalus & 2 & 2 \\
\hline No cause found & 60 & 1.33 \\
\hline
\end{tabular}

Table 2: Onset and induction of labour.

\begin{tabular}{|llc|}
\hline $\begin{array}{l}\text { Onset of labour } \\
\text { Spontaneous } \\
\text { onset of labour }\end{array}$ & 67 & 44.67 \\
\hline $\begin{array}{l}\text { Induction with } \\
\text { prostaglandins/ } \\
\text { intracervacal }\end{array}$ & 83 & 55.33 \\
\begin{tabular}{l} 
Foleys catheter \\
\hline
\end{tabular}
\end{tabular}

Table 3: Augmentation with oxytocin.

\begin{tabular}{|lll|}
\hline $\begin{array}{l}\text { Augmentation } \\
\text { with oxytocin }\end{array}$ & Number of cases & Percentage \\
\hline Required & 135 & 90 \\
\hline Not required & 15 & 10 \\
\hline
\end{tabular}

Besides, 90\% women who presented with spontaneous onset of labour delivered vaginally and CS was mostly required in the induction group.

Duration of labour was $<12$ hours in $30(31.25 \%)$ women and $66(68.25 \%)$ had labour $>12$ hours. Table 4 shows the mode of delivery in all the 150 women.

Table 4: Mode of delivery.

\begin{tabular}{|lll|}
\hline Mode of delivery & Number of cases & Percentage \\
\hline $\begin{array}{l}\text { Spontaneous } \\
\text { Vaginal delivery }\end{array}$ & 89 & 59.33 \\
\hline $\begin{array}{l}\text { Assisted vaginal } \\
\text { delivery }\end{array}$ & 7 & 4.67 \\
\hline LSCS & 54 & 36.00 \\
\hline
\end{tabular}

Indication for LSCS in majority of cases was failure to progress $68.52 \%$ and in $24.074 \%$ it was foetal distress and in $7.41 \%$ it was deep transverse arrest (Table 5).
Table 5: Indication of caesarean section.

\begin{tabular}{|lll|}
\hline Indication & $\begin{array}{l}\text { Number of } \\
\text { cases }\end{array}$ & Percentage \\
\hline Arrest of progress & 30 & 55.56 \\
\hline Fetal distress & 20 & 37.03 \\
\hline $\begin{array}{l}\text { Deep transverse } \\
\text { arrest }\end{array}$ & 4 & 7.41 \\
\hline
\end{tabular}

Table 6: Maternal outcome..

\begin{tabular}{|lll|}
\hline $\begin{array}{l}\text { Maternal } \\
\text { morbidity }\end{array}$ & $\begin{array}{l}\text { Number of } \\
\text { cases }\end{array}$ & Percentage \\
\hline Perineal tears & 5 & 3.33 \\
\hline Cervical tear & 2 & 1.33 \\
\hline PPH & 16 & 10.67 \\
\hline $\begin{array}{l}\text { Wound } \\
\text { infection }\end{array}$ & 8 & 5.33 \\
\hline $\begin{array}{l}\text { Prolonged } \\
\text { hospital stay }\end{array}$ & 2 & 1.33 \\
\hline
\end{tabular}

Regarding maternal outcome, postpartum haemorrhage (PPH) occurred in $16(10.67 \%)$ women, perineal tear in 5 $(3.33 \%)$, wound infection in $8(5.33 \%)$, cervical tear in 2 $(1.33 \%)$ and prolonged hospital stay in $2(1.33 \%)$ cases (Table 6).

Regarding foetal outcome, Apgar score at 5 minute was $7-10$ in $113(75.33 \%)$, 4-6 in $30(20 \%), 3$ and below in $7(4.67 \%)$ neonates. $14(9.33 \%)$ neonates required admission to neonatal intensive care unit (NNICU), while meconium aspiration was noted in $7(4.67 \%)$.

Table 7: Perinatal outcome.

\begin{tabular}{|ll|l|}
\hline Fetal outcome & $\begin{array}{l}\text { Number of } \\
\text { cases }\end{array}$ & Percentage \\
\hline $\begin{array}{l}\text { Apgar score at } 5 \\
\text { minute }\end{array}$ & & 75.33 \\
$7-10$ & 113 & 20.00 \\
$4-6$ & 30 & 4.67 \\
3 and less & 7 & 9.33 \\
\hline $\begin{array}{l}\text { Admission to } \\
\text { NNICU }\end{array}$ & 14 & 2.00 \\
\hline $\begin{array}{l}\text { Neonatal } \\
\text { intubation }\end{array}$ & 3 & 4.67 \\
\hline $\begin{array}{l}\text { Meconium } \\
\text { aspiration }\end{array}$ & 7 & 0.67 \\
\hline $\begin{array}{l}\text { Early neonatal } \\
\text { death }\end{array}$ & 1 & \\
\hline
\end{tabular}

\section{DISCUSSION}

This study was carried out on 150 primigravida with unengaged head at term and at onset of labour, which was aimed at finding out the aetiological factors, outcome of labour, medical and surgical interventions required. An important observation of the study was that no cause could be ascertained in $40 \%$ of the population. The main 
causes of high head identified were deflexed head and CPD. A similar result was documented by other studies. ${ }^{9-}$

Friedman et $\mathrm{al}^{14}$ stated that in primigravidas with high head, latent phase is increased and mean duration of labour was $14.4 \mathrm{hrs}$. In our series, in $66(68.25 \%)$ of the patients labour lasted more than $12 \mathrm{hrs}$. The causes in these patients were improper adaptation of presenting part, high station at the beginning of the labour, deflexed head, misdirection of uterine expulsive forces, high incidence of rupture of membranes and dry labour and ineffective uterine contractions which is in consistence with the previous studies. ${ }^{4,7,13,14}$

The rate of caesarean sections in such cases was $36 \%$ as compared to overall $15 \%$ incidence of caesarean sections. These results were consistent with the results of many studies e.g., Ambwani et al stated that the rate of caesarean section in his study was $34 \%$ in patients with unengaged heads at term, Nadia Khurshid et al had 33\% LSCS rate and Salma Iqbal et al has 38\% LSCS rate but according to Debby $82.9 \%$ of the women with high heads delivered vaginally and $17.1 \%$ had a caesarean section which was quite less than our findings, possible cause may be many of women with unengaged heads needed induction and there was greater need for augmentation of labour in our study. $3,4,6,7$

In the present study, 55.56\% underwent LSCS for failure to progress and foetal distress was second common indication $37.03 \%$ and $7.41 \%$ underwent LSCS for DTA. Compared with study by Chaudhary et al. ${ }^{15}$ Caesarian were performed due to failure to progress $48 \%$ for foetal distress in $24 \%$ and $8 \%$ underwent LSCS for DTA.

We had one case of perinatal mortality, a baby delivered by forceps died after 5 day because of meconium aspiration syndrome with severe asphyxia. Maternal complications like postpartum haemorrhage (PPH) occurred in $16(10.67 \%)$ women, perineal tear in 5 $(3.33 \%)$, wound infection in $8(5.33 \%)$, cervical tear in 2 $(1.33 \%)$ and prolonged hospital stay in $2(1.33 \%)$ cases. similar to Shaikh F et al. ${ }^{13}$

According to a study, the single most important predictor for vaginal delivery in women with unengaged head was natural onset of labour therefore all such women who are or have to be induced should be counselled cautiously for a possible caesarean section. ${ }^{16}$ This is also to be noted that unengaged head at term should not by itself be the indication for early delivery by caesarean section. So this can safely be claimed that a vigilant approach and timely intervention can go a long way in reducing the incidence of caesarean sections and hence overall cost and morbidity in these cases.

\section{CONCLUSIONS}

The cause of anaemia in pregnancy and their frequency are dependent on multiple factors such as geography, ethnicity, nutritional status, pre-existing iron status and prenatal iron supplementation, so treating anaemia should start at the conceptional level itself by giving iron prophylaxis for adolescent girls to avoid having anaemic mothers in the beginning of their conception, treating anaemic mothers so that the child is born with adequate iron stores, care of the girl child, proper nutritional supplementation in infancy and childhood by educating the mother and the society as a whole and women should be economically empowered and good antenatal care must be made available and accessible to all of them. Even with routine iron prophylaxis in pregnancy, still the prevalence of anaemia is high, so should we consider one or two doses of routine parenteral iron therapy for all pregnant women? A question which needs to be answered in future by larger studies.

\section{Funding: No funding sources \\ Conflict of interest: None declared}

Ethical approval: The study was approved by the Institutional Ethics Committee

\section{REFERENCES}

1. Cunningham FG, Leveno KJ, Bloom SL, Hauth JC, Gilsirap LC III, Wenstroom KD. Williams Obstetrics. $22^{\text {nd }}$ ed. Stanford, USA: Appleton and Lange; 1997. pp. 153-60, 415-24, 496-501.

2. Dwight JR, John ES. Normal labour, delivery, newborncare and puerperium. In: Danforths Obstetricsand Gynecology. 9th edition. 530 Wallnet street Philadelphia:Lippincott Williams \& Willikans. 2003:35-7.

3. Debby A, Rotmenseh S, Girtler O, Sadan O, Golan A,Glezerman M. Clinical significance of the floating head in nulliparous women in labour. J Reprod Med. 2003;48(1):37-40.

4. Ambwani BM. Primigravida with floating head at term or onset of labour. The Internet Journal of Gynecologyand Obstetrics 2004;3(1).

5. Charles G Slipp. The primigravida in labour with high fetal station. 1969;104:267-72.

6. Iqbal S, Sumaira S. Outcome of primigravida with unengaged versus engaged fetal head at term or onset of labour. Biomedica. 2009;25:159-62.

7. Khurshid N, Sadiq F. Management of primi gravida with unengaged head at term. (Online) (Cited 2015 june 06). Available from URL: http:// pjmhsonline.com. 2012;1-4.

8. Kerr M. Operative obstetrics. 1980:14-6,43,51$3,67,135,148,161$.

9. Mokasha FM .Comparison of pregnancy \& labour in teen agers and primi gravida aged 21-25 years in Transkei. S Afr Med J. 1992;81:421-3.

10. Trevino Tamez G, Puent GK. Indicationsfor caesarean section: Review of 300 cases. Ginecol 
Obstet Mex. 1998;66:411-3.

11. Gayam A. Obstucted labour at a district hospital. Ethiop Med J. 2002;40:11-8.

12. Ansari S, Akhtar S, Aamir M. Causes and management of high foetal head in primi gravida at term. Pak Armed forces Med J. 2008;58:16-20.

13. Shaikh F, Shaikh N. Outcome of primigravida with high head at term. J Pak Med Assoc. 2014;64(9):1012-4.

14. Friedman EA, Sachtleben MR. Station of fetal presenting part. VI. Arrest of descent in nulliparas. Obstet Gynecol. 1976;47:129-36

15. Chaudhary S, Farrukh R, Dar A, Humayun S.
Outcome of labour in nullipara at term with unengaged vertex. J Ayub Med Coll Abbottabad. 2009;21(3):131-4.

16. Saqib N, Saleem F, Saima R. Primigravidae with unengaged fetal head at term: an audit of delivery outcome. Ann King Edward Med Coll. 1999;5(2):177-9.

Cite this article as: Mahajan N, Mustafa S, Tabassum S, Fareed P. Outcome of high fetal station in Primi-Gravida at term in labour. Int J Reprod Contracept Obstet Gynecol 2016;5:873-7. 